\title{
PHARMACO-ETHOLOGICAL ANALYSIS OF AGONISTIC BEHAVIOR BETWEEN RESIDENT AND INTRUDER MICE: EFFECT OF ANTICHOLINERGIC DRUGS
}

\author{
Hiroyuki YOSHIMURA and Nobuya OGAWA \\ Department of Pharmacology, School of Medicine, Ehime University, \\ Onsen-gun, Ehime 791-02, Japan
}

Accepted July 12, 1982

\begin{abstract}
The resident-intruder paradigm was employed in order to evoke an agonistic behavior in mice. In this situation a resident male mouse has been cohabiting with a female for 5 weeks, and an intruder male mouse is introduced into the resident's home cage. A species-specific pattern of agonistic behavior was observed in all mice. The significance of cholinergic mechanisms in the mediation of the agonistic behavior was evaluated by pharmacological manipulations. Drugs were administered to resident mice. Scopolamine hydrobromide $(0.25,0.50$ and $0.75 \mathrm{mg} / \mathrm{kg}$, i.p.) significantly suppressed the resident's aggressive episodes (offensive sideways posture. tail rattling and attack biting) in a dose-dependent manner, whereas the peripheral anticholinergic drug methylscopolamine nitrate $(0.25,0.50$ and $0.75 \mathrm{mg} / \mathrm{kg}$, i.p.) was ineffective. On the other hand, the resident's locomotor activity and rearing response were significantly increased after the administration of scopolamine hydrobromide. The evidence suggests that brain cholinoceptive mechanisms may participate in the regulation of intraspecies aggressive behavior. However, it appears that other nonspecific behavioral effects of scopolamine cannot be ruled out.
\end{abstract}

Cholinoceptive mechanisms in the brain have been postulated to play an important role in the regulation of nonspecific aggressive and defensive reactions: for example, ragelike reactions in cats and rats that are produced by brain lesion or stimulation and mutual upright postures in pairs of rats or mice that are evoked by electrical foot-shock or drug treatment (1, 2 for review). Interspecies aggression such as mouse-killing behavior in rats induced by olfactory bulbectomy or prolonged isolation housing is also effectively altered by drugs affecting brain cholinergic functions $(3,4)$. The majority of testing procedures, however, require noxious and intense experimental manipulations. This is an important factor which may affect the validity of an animal model in searching for the neuroregulating mechanisms of aggression. Indeed, it has been indicated that the results obtained in pharmacological or behavioral studies are in many cases dependent upon the type of experimental manipulation employed $(5,6)$.

In order to eliminate the complex interactions between aversive situations and crug effects, a resident-intruder paradigm which does not resort to any aversive experimental manipulation has recently been introduced into the pharmacological analysis of agonistic behavior (see ref. 7 for a review). When the resident male mouse which has been cohabiting with a female for several weeks confronts an intruder male in the resident's 
home cage, a species-specific pattern of agonistic behavior can be observed. In this paradigm, virtually all resident male mice exhibit the intraspecies aggressive episodes: namely, offensive sideways posture, tail rattling, and attack biting.

The present study was conducted to investigate the participation of brain cholinergic mechanisms in the mediation of the intraspecies aggressive behavior using a resident-intruder paradigm. Locomotor activity and rearing response during agonistic confrontations were also determined in order to clarify the specificity of the drug effect.

\section{MATERIALS AND METHODS}

Subjects: All animals employed were ICR albino mice obtained from Clea Inc. (Osaka, Japan) at 6 weeks of age. The resident male mice were housed together with an agematched female. The intruder male mice were housed 5 animals per cage. All subjects had free access to food and water and were handled once per week for cage cleaning. Their cage floors were covered with wood shavings. The temperature in a vivarium was maintained at $23 \pm 1^{\circ} \mathrm{C}$, and a $12 \mathrm{hr}$ lightdark cycle was automatically controlled (light on at 7:00 a.m., off at 7:00 p.m.).

Behavioral testing: The apparatus used in studying agonistic behavior was the resident's home cage, made from clear polycarbonate $(21 \times 32 \times 14 \mathrm{~cm})$. At approximately 5 weeks after initial cohabitation, the behavioral testing began: the resident male mouse was confronted in his home cage with a group housed male intruder. The test was started immediately after the introduction of an intruder into the resident's home cage, and it lasted for $5 \mathrm{~min}$ from the time the first attack occurred. The test was terminated if the resident mouse did not attack an intruder within $5 \mathrm{~min}$. Immediately before the introduction of the intruder, the female mouse and. if present, pups were removed. After com- pletion of the test for agonistic behavior, the removed mice were returned to their home cage. In this study, the pairing of resident and intruder animals were fixed throughout the experimental period. Each test was recorded using a video monitor system: and at a later time, the following behavioral elements, based on the definitions by Grant and Mackintosh (8), were scored: offensive sideways posture, tail rattling, attack biting. rearing, and locomotion (ambulation from one position to another position, which excludes chasing or following). During the test period, the observer depressed one key on consoles for as long as each behavioral element occurred. The frequency and duration of each behavioral item were analyzed. Agonistic confrontations were conducted between 13:00 and 16:00.

Drug treatments: Before starting the drug experiments, it was confirmed that resident mice $(n=10)$ reliably attacked intruder mice in at least three or four tests. The following treatment was given to resident mice in a systemically varied sequence, that is, each animal was subjected to all conditions: saline, scopolamine $(0.25,0.50$ and $0.75 \mathrm{mg} /$ $\mathrm{kg})$, and methylscopolamine $(0.25,0.50$ and $0.75 \mathrm{mg} / \mathrm{kg}$ ). Each test was separated by 3 to 4 days from the next. Scopolamine hydrobromide (Merck) and methylscopolamine nitrate (Merck) were dissolved in $0.9 \%$ saline and injected intraperitoneally (1.0 $\mathrm{mi}$ per $100 \mathrm{~g}$ body weight). The injection-test interval was $30 \mathrm{~min}$ for both drug and vehicle.

Statistical analysis: The statistical evaluation was performed by means of analysis of variance, and significant differences between the vehicle control and drug conditions were evaluated by means of the Wilcoxon matchedpairs signed-ranks test.

\section{RESULTS}

In the present experiments, all resident 
males manifested the attack biting when the group housed male intruder was introduced into the resident's home cage. One resident male, however. was excluded from the data because he lost his body weight remarkably during the repeated agonistic confrontations. Retreat, flee, defensive upright posture, and alert posture were often shown by the intruder only as immediate reactions to attack bitings, chasing, and offensive sideways posture.

The effect of anticholinergic drugs on the resident's aggressive episodes is shown in Fig. 1. Analysis of variance revealed a significant difference in each of the behavioral items among the treatments: offensive sideways posture, $F(6.48)=8.81, P<0.001$; attack biting, $F(6,48)=20.52, P<0.001$; and tail rattling, $F(6,48)=7.49, P<0.001$. An intraperitoneal injection of scopolamine hydrobromide $(0.25,0.50$ and $0.75 \mathrm{mg} / \mathrm{kg}$ ) significantly suppressed these aggressive episodes in a dose-dependent manner. However, suppressive effects of the drug at a dose of $0.25 \mathrm{mg} / \mathrm{kg}$ on both offensive sideways posture and tail rattling were not statistically reliable. At the highest dose, 4 out of 9 resident mice failed to exhibit any of the aggressive episodes. By contrast, a peripheral anticholinergic drug. methylscopolamine nitrate $(0.25,0.50$ and $0.75 \mathrm{mg} /$ $\mathrm{kg}$, i.p.), did not show any significant suppression of these behavioral items.

As shown in Fig. 2, the resident's
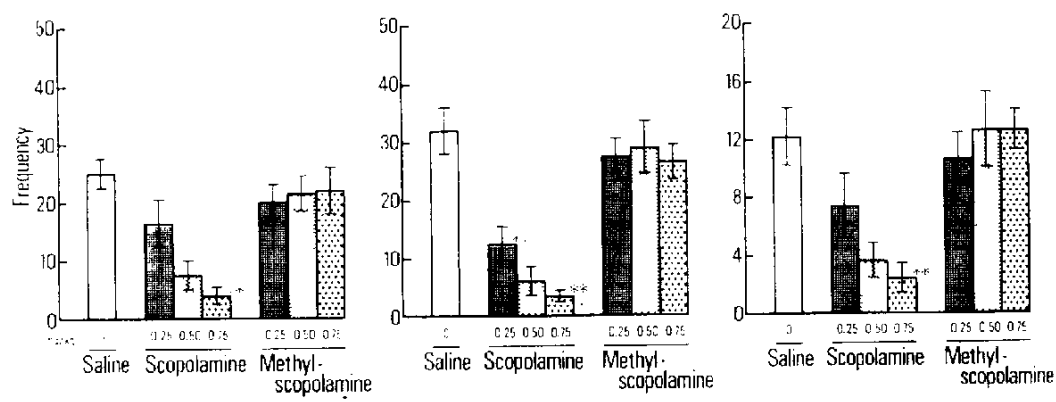

Fig. 1. Effect of anticholinergic drugs on resident's aggressive elements. Left: offensive sideways posture. Middle: attack biting. Right: tail rattling. ${ }^{*} \mathrm{P}<0.01$, significantly different from the saline control.
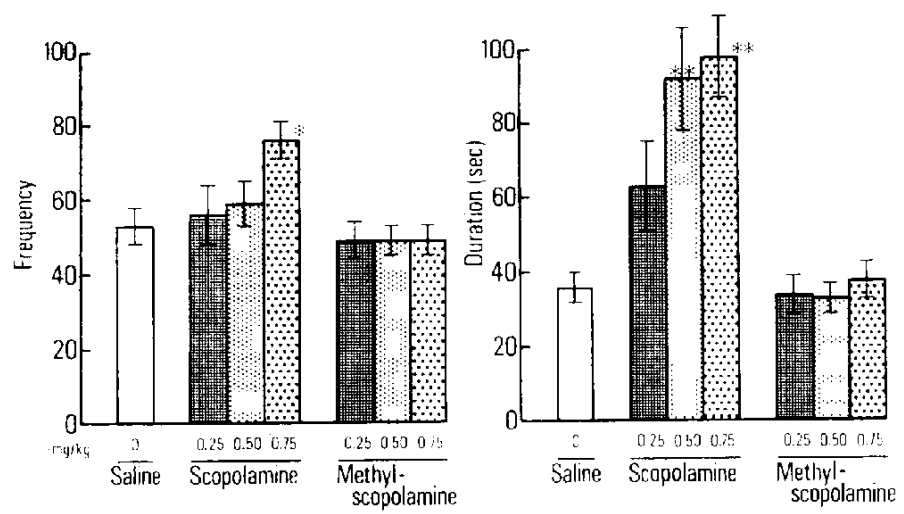

Fig. 2. Effect of anticholinergic drugs on resident's locomotor activity. Left: frequency and Right: duration. $" \mathrm{P}<0.05,{ }^{*} \mathrm{P}<0.01$; significantly different from the saline control. 

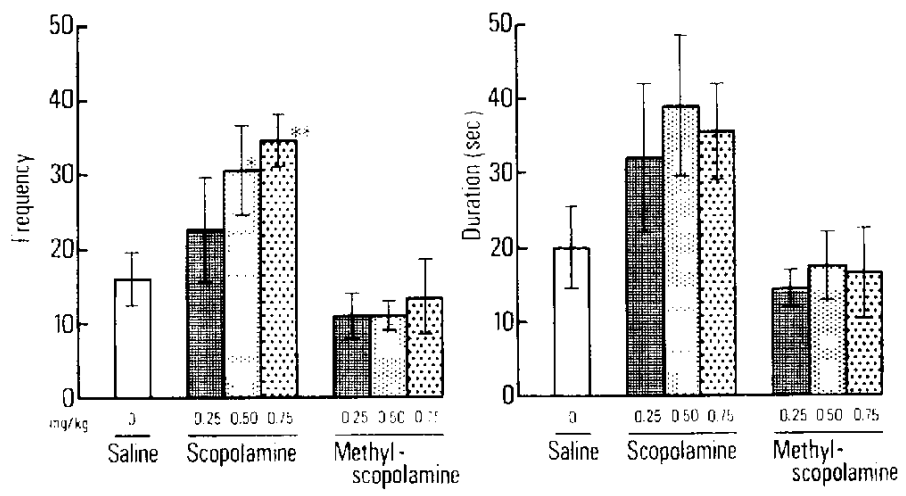

Fig. 3. Effect of anticholinergic drugs on resident's rearing response. Left: frequency and Right: duration. "P< $0.05,{ }^{* *} P<0.01$ : significantly different from the saline control.

locomotor activity under the agonistic confrontation was also affected significantly by the anticholinergic drug: frequency, $F(6$. $48)=4.03, P<0.01$ and duration, $F(6$, $48)=9.08, P<0.001$. The frequency of $10 \mathrm{co}-$ motion during the $5 \mathrm{~min}$ test period was significantly increased by $0.75 \mathrm{mg} / \mathrm{kg}$ of scopolamine as compared with the saline control $(P<0.05)$. The drug effect on the duration of locomotion was more clear-cut than the effect on frequency: namely. scopolamine at doses of 0.50 and $0.75 \mathrm{mg} /$ $\mathrm{kg}$ produced about two-fold longer duration than that of saline control $(P<0.01)$. Methylscopolamine did not affect the resident's locomotor activity at all dose levels employed.

Figure 3 shows the effect of anticholinergic drugs on the rearing response. Analysis of variance revealed a significant difference in both frequency and duration of rearing among the treatments: frequency, $F(6$. $48)=5.94, \quad P<0.001$ and duration, $F(6$. $48)=2.82, P<0.05$. As compared with the saline control, scopolamine significantly increased the frequency of rearing at doses of $0.50(P<0.05)$ and $0.75 \mathrm{mg} / \mathrm{kg}(P<0.01)$. The duration of rearing was also prolonged by the drug, but it was not statistically significant. Methylscopolamine at all doses did not show any significant effect on both the frequency and the duration of rearing response.

\section{DISCUSSION}

Among the stimuli which evoke intraspecies fighting behavior in a wide variety of animal species, the appearence of the stranger in an animal's living space is the strongest (9). In fact, the present results indicate clearly that all resident mice fight in their home cage against an intruder by threat, chasing and attack biting. Thus, there seems to be no doubt that the fighting between resident and intruder mice is primarily based on their territoriality: territorial aggression.

Since the peripherally injected methylscopolamine nitrate at the employed doses would not be expected to cross the blood brain barrier, the differential suppression of aggressive behavior is due to the central action of scopolamine hydrobromide and is viewed as evidence favoring the hypothesis of the cholinergic regulation of aggression. Similar suppressive effects of scopolamine on aggression have been reported in a variety of test situations: isolation-induced fighting (10). mutual-upright posture elicited by electrical foot shock (11), and mousekilling behavior induced by olfactory bulbectomy (4). However, there is a discrepancy in the effective dose of scopolamine, depending upon the employed manipulation; and it is 
noteworthy that our paradigm is more sensitive to the drug action. Interestingly, it has been indicated that a centrally active anticholinergic drug can suppress the scent marking behavior in gerbils (12) which is considered an important form of social communication closely related to territoriality and dominancy $(13,14)$.

There arises, however, a question as to whether or not an anticholinergic drug affects specifically only the aggressive behavior of the attacking animal. In fact, the present study shows that scopolamine evoked the increase of locomotor and rearing activities in a dose-dependent manner. Thus, it is conceivable that the increased motor activity by scopolamine may conceal the speciesspecific pattern of aggression. Indeed, scopolamine is known to exert a wide variety of effects on animal behavior: for example. reduction of fear and species-specific defense reaction (15), impairment of habituation to novelty (16), deficits in passive avoidance (17). decrease of punishment suppressed behavior (18), and disruption of maintenance of attention (19). Although it has been generally accepted that the release of ACh and activation of cholinoceptive mechanisms play an essential role in the maintenance of aggressive behavior, this view is mainly based on pharmacological evidence; and the neurochemical findings such as ACh contents (20). $\mathrm{ACh}$ turnover rate (21), and cholinergic enzyme activities in discrete brain areas (4) do not fit the results of pharmacological analyses. Therefore, it appears that nonspecific components of the drug effect including an alteration of other neural activities cannot be ruled out.

The resident-intruder paradigm features several advantages in comparison with other tests: reliable initiation of fighting behavior by the resident animal, high incidence of agonistic behavior, manifestation of speciesspecific pattern of agonistic behavior, no requirement of aversive stimuli, persistent and stable level of agonistic behavior during consecutive encounters (unpublished data by Yoshimura and Miczek), species generality ranging from rodents to primates $(22,23)$. The most important aspects of the paradigm is that one can avoid the complex interactions between aversive stimuli, aggression and drug effect.

Acknowledgements: This study was supported in part by a Grant-in-Aid for Scientific Research (C. 56570079) to N. Ogawa, and by a Grant-in-Aid for Encouragement of Young Scientists to $\mathrm{H}$. Yoshimura, from the Ministry of Education. Science and Culture, Japan. We thank Miss Misuzu Kurokawa for skillful technical assistance.

\section{REFERENCES}

1) Allikmets, L.H.: Cholinergic mechanisms in aggressive behavior. Med. Biol. 52, 19-30 (1974)

2) Miczek, K.A. and Barry, H., IIl.: Pharmacology of sex and aggression. In Behavioral Pharmacology. Edited by Glick. S.D. and Goldfarb. J., p. 176-257, Mosby. St Louis (1976)

3) Yoshimura, H. and Ueki, S.: Biochemical correlates in mouse-killing behavior by the rat: Prolonged isolation and brain cholinergic function. Pharmacol. Biochem. Behav. 6, 193196 (1977)

4) Yoshimura, $H$. : Regional changes in brain cholinergic enzyme activities after bilateral olfactory bulbectomy in relation to mousekilling behavior by rats. Pharmacol. Biochem. Behav. 15, 517-520 (1981)

5) Malick, J.B.: Pharmacological antagonism of mouse-killing behavior in the olfactory buib lesion-induced killer rat. Aggress. Behav. 2, $123-130(1976)$

6) Yoshimura, $H$. and Ueki, S.: Mouse-killing and hyperemotionality in rats induced by three different kinds of experimental manipulations: A comparative study. Physiol. Psychol. 9, 269275 (1981)

7) Miczek, K.A. and Krsiak, M.: Drug effects on agonistic behavior. In Advances in Behavioral Pharmacology. Edited by Thompson, T. and Dews, P.B., p. 87-162. Academic Press, New York (1979)

8) Grant, E.C. and Mackintosh, J.H.: A com- 
parison of the social postures of some common laboratory rodents. Behavior 21, 246-259 (1969)

9) Wilson, E.O.: Sociobiology. The new synthesis. Belknap Press, Cambridge, Mass. (1975)

10) DaVanzo, J.P., Daugherty, M., Ruckart, R. and Kang. L.: Pharmacological and biochemical studies in isolation-induced fighting mice. Psychopharmacologia (Berlin) 9, 210-219 (1966)

11) Powell, D.A., Milligan, W.L. and Walters, K.: The effects of muscarinic cholinergic blockade upon shock-elicited aggression. Pharmacol. Biochem. Behav. 1, 389-394 (1973)

12) Yoshimura, H.: Cholinergic mecharisms in scent marking behavior by Mongolian gerbils (Meriones unguiculatus). Pharmacol. Biochem. Behav. 13, 519-523 (1980)

13) Yoshimura, $H$. : Behavioral characteristics of scent marking behavior in the Mongolian gerbil (Meriones unguiculatus). Exp. Anim. 30, 107112 (1981)

14) Thiessen, D.D. and Rice, M.: Mammalian gland marking and social bchavior. Psychol. Bull. 83, 505-539 (1976)

15) Plotnik, R., Mollenauer, S. and Snyder, E.: Fear reduction in the rat following central cholinergic blockade, J. Comp. Physiol. Psychol. 86, 1074-1082 (1974)

16) Leaton, R.N.: Effects of scopolamine on exploratory motivated behavior. J. Comp. Physiol.
Psychol. 66, 524-527 (1968)

17) Calhoun, W.H. and Smith, A.A.: Effects of scopolamine on acquisition of passive avoidance. Psychopharmacologia (Berlin) 13, 201209 (1968)

18) Miczek, K.A.: Effects of scopolamine, amphetamine and chlordiazepoxide on punishment. Psychopharmacology (Berlin) 28, 373-389 (1973)

19) Cheal, M.L.: Scopolamine disrupts maintenance of attention rather than memory processes. Behav. Neural. Biol. 33, 163-187 (1981)

20) Yoshimura, H., Gomita, Y. and Ueki, S.: Changes in acetylcholine content in rat brain after bilateral olfactory bulbectomy in relation to mouse-killing behavior. Pharmacol. Biochem. Behav. 2, 703-705 (1974)

21) Karczmar, A.G. and Kindel, G.H.: Acetylcholine turnover and aggression in related three strains of mice. Prog. Neuropsychopharmacol. 5, 35$48(1981)$

22) Miczek, K.A., Woolley, J., Schlisserman, S. and Yoshimura, H.: Analysis of amphetamine effects on agonistic and affiliative behavior in Squirrel monkeys (Saimiri sciureus). Pharmacol. Biochem. Behav. 14, Supp. 1, 103-107 (1981)

23) Miczek, K.A. and Yoshimura, H.: Disruption of primate social behavior by d-amphetamine and cocaine: Differential antagonism by antipsychotics. Psychopharmacology (Berlin) 76. $163-171(1982)$ 